\title{
Invasive fungal infection by Cryptococcus neoformans var. grubii with bone marrow and meningeal involvement in a HIV- infected patient: a case report
}

Hareton Teixeira Vechi ${ }^{1 *}$ D, Raquel Cordeiro Theodoro ${ }^{2}$, Andrea Lima de Oliveira ${ }^{2}$, Ronald Muryellison Oliveira da Silva Gomes², Rodolfo Daniel de Almeida Soares ${ }^{3}$, Munya Gandour Freire ${ }^{4}$ and Mônica Baumgardt Bay ${ }^{1}$

\begin{abstract}
Background: Cryptococcosis is a common opportunistic infection in patients infected by Human Immunodeficiency Virus (HIV) and is the second leading cause of mortality in Acquired Immunodeficiency Syndrome (AIDS) patients worldwide. The most frequent presentation of cryptococcal infection is subacute meningitis, especially in patients with a CD4+ T Lymphocytes count below 100 cells/ $\mu \mathrm{L}$. However, in severely immunosuppressed individuals Cryptococcus neoformans can infect virtually any human organ, including the bone marrow, which is a rare presentation of cryptococcosis.

Case presentation: A 45-year-old HIV-infected male patient with a CD4+ T lymphocyte count of 26 cells/uL who presented to the emergency department with fever and pancytopenia. Throughout the diagnostic evaluation, the bone marrow aspirate culture yielded encapsulated yeasts in budding, identified as Cryptococcus sp. The bone marrow biopsy revealed a hypocellularity for age and absence of fibrosis. It was observed presence of loosely formed granuloma composed of multinucleated giant cells encompassing rounded yeast like organisms stained with mucicarmine, compatible with Cryptococcus sp. Then, the patient underwent a lumbar puncture to investigate meningitis, although he had no neurological symptoms and neurological examination was normal. The cerebrospinal fluid culture yielded Cryptococcus sp. The species and genotype identification step showed the infection was caused by Cryptococcus neoformans var. grubii (genotype VNI). The patient was initially treated with amphotericin B deoxycholate plus fluconazole for disseminated cryptococcosis, according to guideline recommendations. However, the patient developed acute kidney injury and the treatment was switched for fluconazole monotherapy. The symptoms disappeared completely with recovery of white blood cells and platelets counts. Cerebrospinal fluid cultures for fungi at one and two-weeks of treatment were negative.
\end{abstract}

Conclusions: Bone marrow infection caused by Cryptococcus neoformans is a rare presentation of cryptococcosis. The cryptococcal infection should be included for differential diagnosis in HIV-infected patients with fever and cytopenias, especially when CD4+ T lymphocytes count is below 100 cells/ $\mathrm{LL}$.

Keywords: Cryptococcosis, Cryptococcus neorformans, AIDS, HIV, Bone marrow

\footnotetext{
* Correspondence: haretonvechi@gmail.com

'Department of Infectious Diseases, Hospital Giselda Trigueiro, Universidade

Federal do Rio Grande do Norte, 110 Cônego Monte Street, Natal, Rio

Grande do Norte RN 59037-170, Brazil

Full list of author information is available at the end of the article
}

(c) The Author(s). 2019 Open Access This article is distributed under the terms of the Creative Commons Attribution 4.0 International License (http://creativecommons.org/licenses/by/4.0/), which permits unrestricted use, distribution, and reproduction in any medium, provided you give appropriate credit to the original author(s) and the source, provide a link to the Creative Commons license, and indicate if changes were made. The Creative Commons Public Domain Dedication waiver (http://creativecommons.org/publicdomain/zero/1.0/) applies to the data made available in this article, unless otherwise stated. 


\section{Background}

Cryptococcosis remains the second most frequent cause of death in AIDS patients worldwide, only behind tuberculosis [1]. Its most frequent presentation is subacute meningitis, which ranges from 70 to $90 \%$ of cases [2], usually in patients with CD4+ T lymphocyte count bellow 100 cells $/ \mu \mathrm{L}$ [3]. Recent estimates suggest that about 223,000 new cases of cryptococcal meningitis are diagnosed every year, causing 181,000 deaths [1]. Cases usually occur in patients who are unaware of their HIV infection, being cryptococcosis their AIDS-defining illness, or in those with limited access to antiretroviral therapy [4]. In both situations, cryptococcal infection indicates a failure in AIDS control programs.

In turn, HIV-infected patients with severe immunodeficiency commonly present fever accompanied with cytopenias. The hematological abnormalities can be due to HIV infection itself or non-infectious and infectious causes. The most frequent opportunistic infections that cause pancytopenia are histoplasmosis and mycobacteriosis [5]. In severely immunosuppressed patients, Cryptococcus neoformans can infect virtually any human organ system, including the bone marrow, which is a rare presentation of cryptococcosis.

Here, we describe an uncommon presentation of disseminated cryptococcosis with invasive disease of bone marrow and asymptomatic meningitis.

\section{Case presentation}

A 45-year-old HIV-infected black man, mechanic, has sought emergency department referring progressive asthenia for two weeks, with difficulty on performing basic daily life activities, anorexia, fever and profuse sweating. During this time, he reported a weight loss of $3 \mathrm{Kg}$. In the last $24 \mathrm{~h}$, he had vomiting episodes preceded by nausea, in small volume, without relation to feeding. The patient denied other symptoms like headache, cough, abdominal pain and diarrhea. The HIV infection was diagnosed 8 years ago and his current antiretroviral therapy consisted of tenofovir disoproxil fumarate - lamivudine efavirenz in a once-daily single-pill. His medical history was remarkable for poor adherence to antiretroviral therapy. His recent CD4+ and CD8+ T lymphocytes counts were 26 (1.92\%) and 509 (37.9\%) cells/ $\mu \mathrm{L}$ respectively and the viral load was 252,624 copies/mL $\left(5.402 \log _{10}\right)$. He was also using a trimethoprim-sulfamethoxazole double-strength tablet for Pneumocystis jirovecii prophylaxis. The patient had pulmonary tuberculosis 8 years ago, his AIDS-defining illness. In addition, he had several previous hospitalizations for chronic diarrhea. He used to drink distilled beverages thrice a week and denied tobacco use. The patient raised a dog and a parakeet as pets. He was born in Angicos City, rural area of Rio Grande do Norte, Brazil, an endemic region for visceral leishmaniasis and Chagas disease.
On admission, vital signs were: axillary temperature $38.0^{\circ} \mathrm{C}$, blood pressure $100 / 80 \mathrm{mmHg}$, pulse rate of 110 $\mathrm{bpm}$ and respiration rate of $24 \mathrm{bpm}$. His physical examination was remarkable for cachexia (body weight of $38 \mathrm{Kg}$ and body mass index of $13.9 \mathrm{Kg} / \mathrm{m}^{2}$ ) and a mild hepatomegaly. He was lucid and oriented. There were no signs of meningeal irritation. The neurological examination was normal. Laboratory tests showed pancytopenia: hemoglobin of $100 \mathrm{~g} / \mathrm{L}$; white blood cell counts of $2.7 \times 10^{9} / \mathrm{L}$ (74\% neutrophils and $22 \%$ lymphocytes) and platelets count of $123 \times 10^{9} / \mathrm{L}$. The erythrocyte sedimentation rate was $68 \mathrm{~mm}$ [Reference Interval (RI): $0-15 \mathrm{~mm}$ ] and serum C - reactive protein level was $28.5 \mathrm{nmol} / \mathrm{L}$ (RI: < $57.1 \mathrm{nmol} / \mathrm{L}$ ). The serum creatinine was $0.058 \mathrm{mmol} / \mathrm{L}$ (RI: $0.044-0.106 \mathrm{mmol} / \mathrm{L}$ ) and serum urea was $3.18 \mathrm{mmol} / \mathrm{L}$ (RI: $1.66-8.32 \mathrm{mmol} / \mathrm{L})$. The alanine and aspartate aminotransferases levels were 43 and 23 IU/L (RI: 0-37 and $0-42 \mathrm{IU} /$ $\mathrm{L}$, respectively). The alkaline phosphatase and gamma-glutamyl transferase levels were $201 \mathrm{IU} / \mathrm{L}$ and $49 \mathrm{IU} / \mathrm{L}$ (RI: $80-$ $306 \mathrm{IU} / \mathrm{L}$ and $11-61 \mathrm{IU} / \mathrm{L}$, in this order). The serum albumin was $39.4 \mathrm{~g} / \mathrm{L}$ (RI: $35-55 \mathrm{~g} / \mathrm{L}$ ), total bilirubin level was $8.55 \mu \mathrm{mol} / \mathrm{L}$ (RI: $3.42-20.52 \mu \mathrm{mol} / \mathrm{L}$ ) and prothrombin time and activity were $13.5 \mathrm{~s}$ and $100 \%$ (RI: $9.5-13.5 \mathrm{~s}$ and $\geq$ 70\%). The serum lactate dehydrogenase level was $477 \mathrm{IU} / \mathrm{L}$ (RI: 225 - $450 \mathrm{IU} / \mathrm{L}$ ). Chest X-ray was normal. An abdominal ultrasonography showed hepatomegaly and cholelithiasis.

He has been treated for febrile neutropenia with cefepime for 7 days, without changes in clinical symptoms. Blood cultures were negative for bacteria and fungi. The serologic tests were negative for hepatitis $B$ and $C$, visceral leishmaniasis and Chagas disease. Tuberculin Test was non-reactive. Venereal disease research laboratory (VDRL) testing was negative too. Cryptococcal antigen testing in serum was not performed, because it is not available at our service. Histoplasma antigen testing in urine was negative. Due to pancytopenia, the patient underwent a bone marrow aspirate and biopsy. The direct examination presented a non-specific hypocellularity and was negative for fungi, mycobacteria and hemoparasites. After 5 days, bone marrow aspirate culture yielded encapsulated yeasts in budding on India ink stain, identified as Cryptococcus sp. Then, the patient underwent a lumbar puncture to investigate meningitis. The cerebrospinal fluid (CSF) had a clear appearance, an opening pressure of $160 \mathrm{mmH}_{2} \mathrm{O}$, a cell count of 2 leukocytes, protein of $44 \mathrm{mg} / \mathrm{dL}$ and glucose of $55 \mathrm{mg} / \mathrm{dL}$, and numerous encapsulated yeasts in budding were seen on India ink stain. The CSF culture yielded Cryptococcus sp. Bone marrow aspirate culture was negative for bacteria, mycobacteria and Leishmania sp.

The bone marrow biopsy revealed $30 \%$ of hematopoietic cellularity with representation of the three cellular lineages, characterizing a hypocellular bone marrow for age. The megakaryocytes were present in increased numbers and 
megakaryocytes with mild dysplasia (hypolobated nuclei) were rarely observed. The myeloid series presented a preserved maturation scale with predominance of mature forms and the erythroid lineage was arranged in small islands without particularities. There were typical plasma cells scattered in hematopoietic tissue. Silver staining revealed a delicate network of reticulin fibers without fibrosis. The Masson's trichrome staining showed no collagen fibers deposition. Giemsa, Fite-Faraco and Periodic Acid-Schiff staining were negative. In the mucicarmine staining, it was observed presence of loosely formed granuloma composed of multinucleated giant cells encompassing rounded yeast like organisms compatible with Cryptococcus sp. (Fig. 1).

For species and genotype identification, the isolate was grown on Sabouraud dextrose agar at $37^{\circ} \mathrm{C}$ for $48 \mathrm{~h}$ and deoxyribonucleic acid (DNA) was extracted by initial mechanical rupture of yeast cell in liquid nitrogen using a pestle and mortar following the extraction protocol of McCullough et al. [6]. The URA5 gene was amplified by
Polymerase Chain Reaction (PCR) according to the method suggested by Meyer et al. [7]. The isolate was identified as C. neoformans var. grubii (genotype VNI) (Fig. 2).

The patient was treated with amphotericin B deoxycholate at $1 \mathrm{mg} / \mathrm{Kg}$ daily, combined with fluconazole at $800 \mathrm{mg}$ daily given intravenously. After a week of treatment, the patient developed acute kidney injury stage 3, according to the Kidney Disease: Improving Global Outcomes (KDIGO) criteria [8], with increase of serum creatinine and urea levels to $0.185 \mathrm{mmol} / \mathrm{L}$ and 11.98 $\mathrm{mmol} / \mathrm{L}$, respectively. At the discretion of assistant doctor, the treatment was switched for fluconazole at 1200 $\mathrm{mg}$ daily during the remainder of the 14-day induction phase. The patient was conservatively managed for acute kidney injury with return of baseline serum creatinine and urea levels after five weeks. CSF cultures for fungi were negative at one and two-weeks of treatment. After that, the patient was treated with fluconazole at $800 \mathrm{mg}$ daily throughout the 8-week consolidation phase.

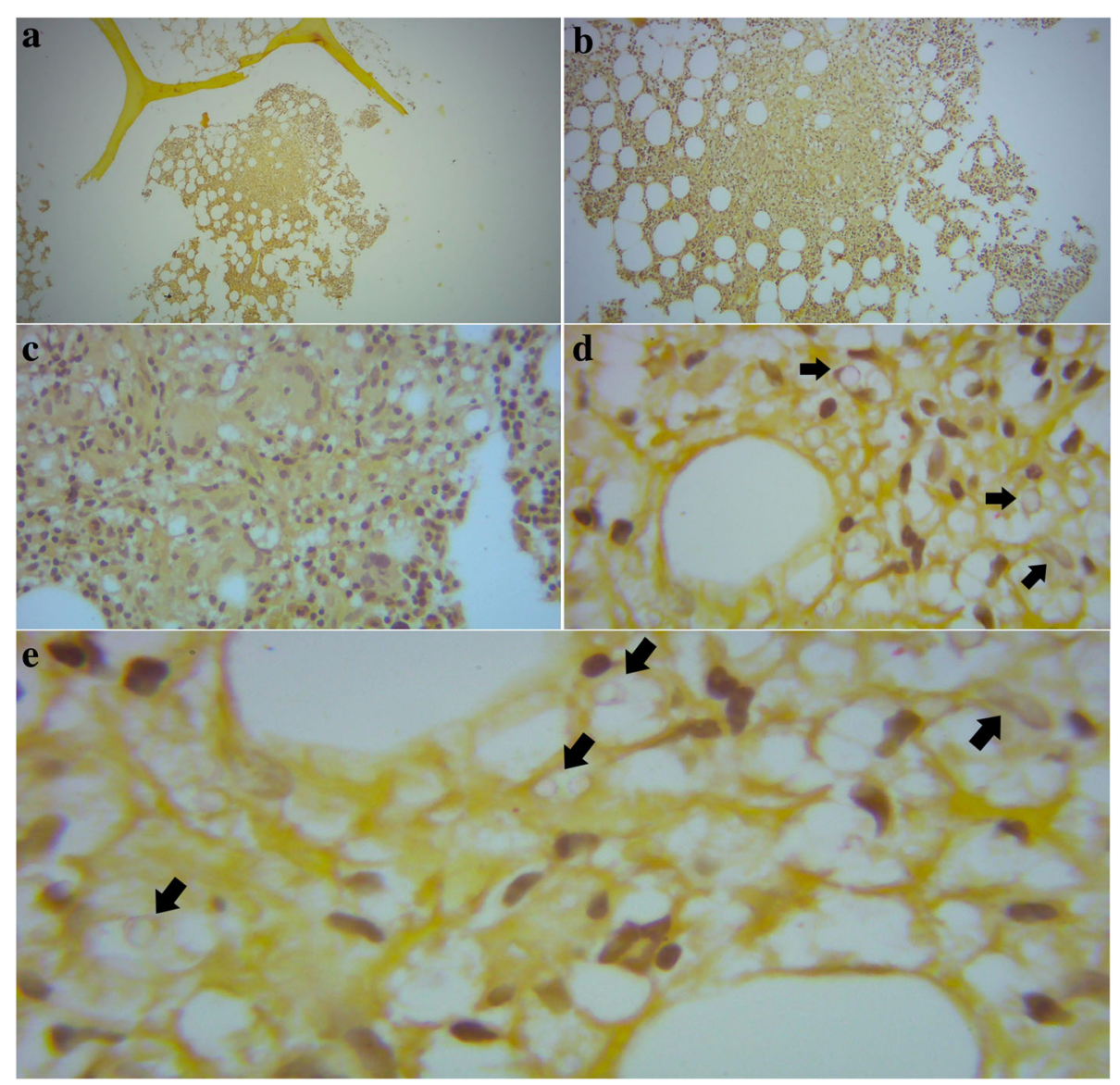

Fig. 1 Photomicrography of the patient's bone marrow biopsy. Effacement of normal bone marrow architecture at 40x and 100x magnification ( $\mathbf{a}$ and $\mathbf{b}$, respectively), with replacement of normal adipose tissue by an inflammatory infiltrate consisting of xanthomatous histiocytes and multinucleated giant cells, constituting a loosely formed granuloma, better visualized at 400x magnification (c). At this magnification, the multinucleated giant cells exhibit clear areas inside their cytoplasm. At 1000x magnification, such clear areas revealed to be rounded yeast like organisms (arrows), located inside multinucleated giant cells and histocytes, stained with mucicarmine in their capsule, compatible with Cryptococcus sp. (d and e) 


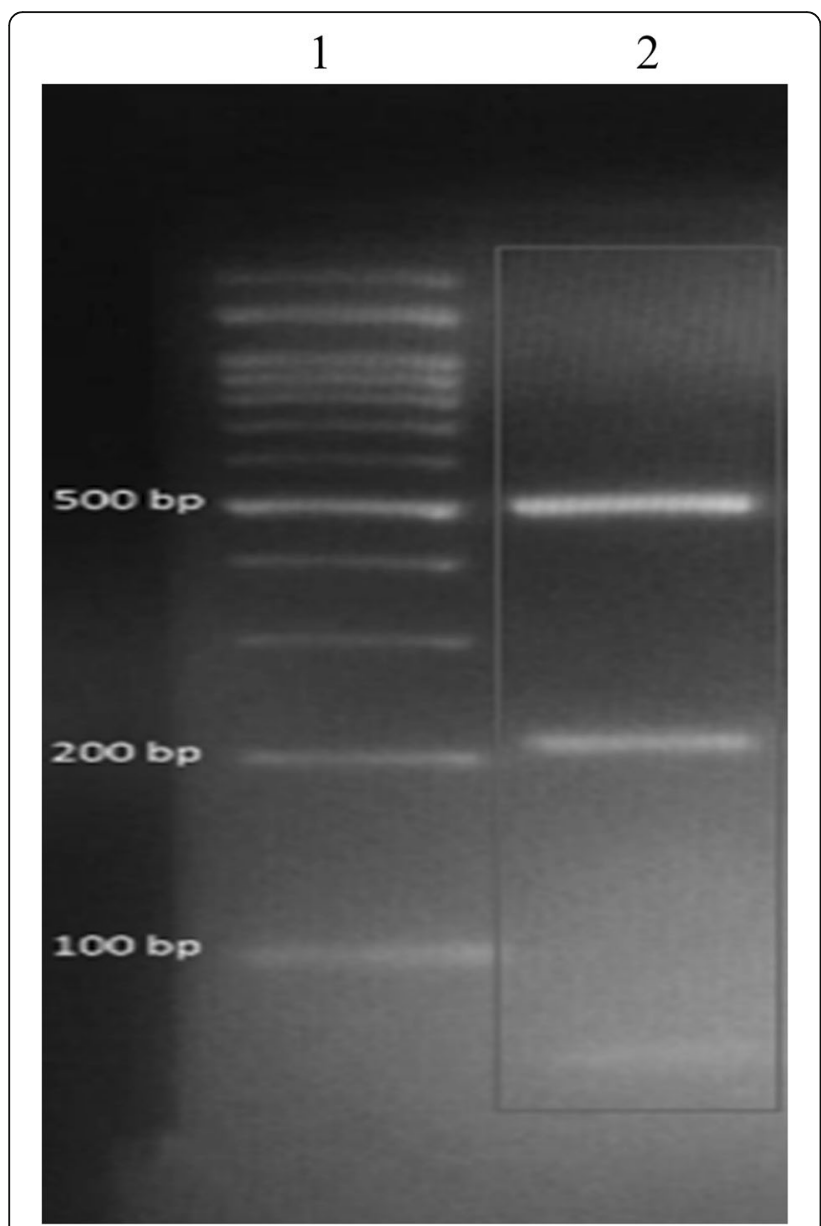

Fig. 2 Genotyping by PCR-RFLP of URA5 gene of Cryptococcus neoformans isolated from patient's bone marrow culture. Lane 1: 100pb DNA ladder. Lane 2: fragments obtained after double digestion of URA5 PCR products

The patient remained hospitalized throughout the induction and consolidation phases of the treatment due to socioeconomic reasons. He could not afford the costs related to the hospitalization neither his medicines, that was why the patient went to our hospital, a public health facility, besides he did not have an appropriate family support to help him recover and manage his condition. Cranial computed tomography (CT) showed cerebellar atrophy with compensatory fourth ventricle ectasia and cerebral atrophy with non-hypertensive dilation of the supratentorial ventricles and enlargement of grooves, fissures and cisterns. Magnetic resonance imaging (MRI) confirmed a non-habitual volumetric reduction of encephalic parenchyma for age with compensatory ectasia of ventricular system; the brain parenchyma signal-intensity was preserved. The patient had no fever nor vomiting within the first week of treatment and recovered from asthenia after four weeks of treatment. After induction and consolidation phases of treatment, the hematological parameters have improved: hemoglobin level of $110 \mathrm{~g} / \mathrm{L}$; white blood cell counts of $5.9 \times 10^{9} / \mathrm{L}$ (65\% neutrophils and $30 \%$ lymphocytes) and platelets count of $166 \times 10^{9} / \mathrm{L}$. He was discharged from hospital with recommendations to keep oral fluconazole at $450 \mathrm{mg}$ daily (maintenance phase) and outpatient follow-up at a regional HIV/AIDS care service.

\section{Discussion and conclusions}

The most frequent clinical manifestation of cryptococcosis in HIV-infected patients is subacute meningitis. Due to the neurotropism, the isolation of Cryptococcus sp. in extra-neural sites should prompt to a lumbar puncture to rule out concomitant meningitis [9]. In the present case, a lumbar puncture was justified after the detection of Cryptococcus neoformans in bone marrow aspirate culture, although the patient did not demonstrate clinical evidences of central nervous system (CNS) involvement. The finding of encapsulated yeasts in CSF was incidental, characterizing a subclinical or latent form of cryptococcal meningitis (CM).

Subclinical CM has previously been reported. Liss and Rimland [10] described two cases of asymptomatic CM. One patient was a 59-year-old diabetic man who was hospitalized for cryptococcal pneumonia. His neurological and ocular examinations were unremarkable and neck stiffness was absent. Blood cultures for fungi were negative. The urine culture yielded Cryptococcus neoformans. He was submitted to a lumbar puncture, with numerous encapsulated yeasts observed in the CSF, subsequently identified as Cryptococcus neoformans.

In a series of 40 cases of CM, Butler and colleagues [11] found four (10\%) cases of asymptomatic CM after isolation of Cryptococcus neoformans in culture of extra-neural sites specimen: kidney, blood, lung, and a submandibular nodule. All patients had no symptoms of meningeal involvement, but one patient has been undergoing psychiatric treatment for personality change of several years duration. Smilack et al. [12] reported a case of a 21-year-old man with widespread Hodgkin's lymphoma in remission with pleural effusion of cryptococcal etiology. He had no neurological symptoms, but Cryptococcus neoformans was also isolated in CSF culture.

The studies of the prevalence of cryptococcal antigenemia in HIV-infected patients with CD4 + T lymphocyte count below 100 cells/ $\mu \mathrm{L}$ demonstrated the $\mathrm{CM}$ may be common in clinical practice. In a recently published meta-analysis, Temfack et al. [13] found a prevalence of $33 \%$ (95\% confidence interval, $21-45 \%$ ) of asymptomatic $\mathrm{CM}$ among cryptococcal antigen ( $\mathrm{CrAg}$ ) positive patients. The CrAg testing has been found to be a valuable tool in the early detection of cryptococcal infection in at-risk patients, as $\mathrm{CrAg}$ can be detected in blood weeks to months before the onset of CM [14]. Since 2011, World Health Organization has recommended routine 
$\mathrm{CrAg}$ testing in antiretroviral-naïve HIV-infected adult patients with $\mathrm{CD} 4+\mathrm{T}$ lymphocyte count below 100 cells $/ \mu \mathrm{L}$, by either latex agglutination or lateral flow assay, followed by a targeted pre-emptive fluconazole therapy among CrAg-positive patients [15].

With pre-emptive fluconazole therapy, the incidence of CM dropped from 21.4 to $5.7 \%$ among CrAg-positive patients and the all-cause mortality reduced from 39.7 to $17.4 \%$, although it still remained significantly higher among CrAg-positive than CrAg-negative patients (around two-fold risk) [13]. Besides blood, $\mathrm{CrAg}$ can be also detected in CSF and has been proved to be a rapid and reliable non-culture-based diagnostic test for confirmed $\mathrm{CM}$ in AIDS patients [16]. CSF CrAg testing is handy for timely diagnosis of $\mathrm{CM}$, as it can be detected before the direct microscopic examination using India Ink is positive, whose sensibility is around $86 \%$, while pending the CSF culture results [17]. Even CSF CrAg may be positive in occasional cases when the culture is negative due to previous exposure to antifungal therapy or the incubation period was not long enough, especially in low yeast burden associated with small volumes of CSF [17].

Unfortunately, the CrAg testing is not available at our service. However, it is worth pointing out that our patient was at high risk for cryptococcosis (CD4+ T lymphocytes count of 26 cells $/ \mu \mathrm{L}$ ) and would probably benefit from $\mathrm{CrAg}$ testing in blood for early detection of the cryptococcal infection, and once being positive, the CSF testing would be advantageous for early and timely diagnosis of meningeal involvement.

As the course of CM is usually indolent over weeks and symptoms and signs may be subtle and non-specific, a high degree of clinical suspicion is required, especially in patients with advanced HIV infection. Vomiting and difficulty on performing basic daily activities, being nonspecific, might be interpreted as neurological symptoms for this patient. In CM, vomiting is often a clinical manifestation of elevated intracranial pressure (ICP). In addition, hydrocephalus, a possible complication of $\mathrm{CM}$ and a cause of elevated ICP, may provoke dementia symptoms with impairment of daily activities. However, the opening pressure of CSF on lumbar puncture was normal and neuroimaging exhibited a normal brain parenchyma sign and excluded cerebral oedema or hydrocephalus as causes of elevated intracranial pressure.

A possible explanation for the asymptomatic meningitis in our patient would be the early diagnosis of CNS involvement. The finding of Cryptococcus neoformans in bone marrow aspirate prompted us to investigate the CNS before the symptoms appeared. Perhaps the atrophy of the brain parenchyma observed in the patient's neuroimaging studies may have contributed to the absence of symptoms slowing the process of increasing ICP. The patient's opening pressure of CSF was $160 \mathrm{mmH}_{2} \mathrm{O}$. Despite this, the pathophysiology related to the symptoms and signs of CM is not fully elucidated.

In the study by Graybill et al. [18], clinical manifestations of raised ICP, as headache, were more common in patients with higher pressures, nevertheless they were absent in up to $8 \%$ of patients with the highest pressures $\left(\geq 350 \mathrm{mmH}_{2} \mathrm{O}\right)$ as well as $79 \%$ of patients with normal ICP $\left(\leq 190 \mathrm{mmH}_{2} \mathrm{O}\right)$ reported headache. In cryptococcal meningitis, elevated ICP is caused by impaired CSF reabsorption at the arachnoid granulations secondary to an inflammatory arachnoiditis or direct cryptococcal infiltration [19]. Shankar et al. [20] raised the hypothesis of impedance of CSF circulation caused by masses of cryptococci on the arachnoid villi leading to dynamic hydrocephalus attacks, which are not recognized by routine methods as cranial CT or MRI in majority of instances.

In addition to CNS infections, HIV-infected patients also have more frequently disseminated cryptococcosis, with the finding of yeasts in extra-neural sites, associated to poorer prognosis $[3,4,9,11]$. Cryptococcus neoformans has been reported to cause infection in any organ of the human body, including the bone marrow. In HIV-positive patients with disseminated cryptococcosis, the bone marrow involvement is observed from 13 to $42 \%$ of cases $[4,11,21]$, with a wide spectrum of clinical manifestations.

Bone marrow infection by Cryptococcus neoformans can be absolutely asymptomatic in HIV-infected patients, and has been identified through screening cultures [21]. It can be an exclusive affection of bone marrow and present nonspecific symptoms like fever, anorexia, asthenia and weight loss as part of a wasting or fever of unknown origin syndrome, followed by pancytopenia [22]. In extreme cases, cryptococcosis can mimic aplastic anemia, with bone marrow biopsy showing almost complete acellularity in context of a disseminated disease [12].

The direct examination of bone marrow aspirate can show extra- and intracellular encapsulated yeast like organisms in budding or not, offering the advantage of a rapid turn-around time, while pending culture and biopsy results [22-24]. In biopsy study, the most common findings are the presence of granulomas with spherical encapsulated yeast $[10,22,25]$, similar to direct examination. Specific stains as India ink, mucicarmine or Gomori methenamine silver are necessary for demonstration of the capsule and confirm the diagnosis of cryptococcosis [22-24]. The isolation of Cryptococcus neoformans from tissue culture adds to diagnosis.

Here in Rio Grande do Norte, a state of Northeast of Brazil, there are other more frequent opportunistic causes of pancytopenia in patients with AIDS as visceral leishmaniasis, disseminated histoplasmosis and tuberculosis. Thus, even though pancytopenia may result from cryptococcosis, the diagnosis was completely unexpected. Our 
patient has fulfilled the criteria for invasive fungal infection of bone marrow by Cryptococcus neoformans. The culture of bone marrow aspirate for fungi requires a volume of 1 to $5 \mathrm{~mL}$. Collecting this volume leads to an unavoidable dilution of bone marrow aspirate with peripheral blood [26]. The yield of Cryptococcus sp. from this culture may result from: the true presence of yeast in bone marrow tissue; the presence of yeasts in peripheral blood (as part of cryptococcaemia) or both. In this case, the peripheral blood culture for fungi, incubated for 8 weeks, as part of diagnostic work-up of disseminated histoplasmosis, was negative. Moreover, the presentation of granulomatous reaction with encapsulated yeasts inside multinucleated giant cells is an unequivocal evidence of bone marrow infection by Cryptococcus sp.

In immunocompromised patients, the cryptococcal disease may result from either primary infection or reactivation of a latent infection. There are epidemiological and biological evidence of the role of quiescence on pathogenesis of cryptococcosis $[27,28]$. In study by Saha et al. [29], the transplant recipients with previous serological evidence of cryptococcal infection (latent infection) developed cryptococcosis earlier after transplant (5.6 \pm 3.4 months) than patients without preexisting serological reactivity ( $40.6 \pm 63.8$ months), suggesting an acute infection in the latter group. In this case, the patient was not very adherent to antiretroviral therapy and his CD4+ $\mathrm{T}$ Lymphocyte count has been below 100 cells $/ \mu \mathrm{L}$ for around 6 years (data not showed).

Furthermore, this patient had a remarkable epidemiological record of parakeet exposure. Cryptococcus neoformans has been isolated from the droppings of a variety of avian species [30]. Although a history of bird exposure is not commonly evoked from patients with cryptococcosis, there are documented cases of probable transmission of Cryptococcus sp. from exposure to aerosolized birds excrements to immunocompromised patients, suggesting a progressive primary infection [31,32]. Taking into account the parakeet exposure and presentation of cryptococcosis after about 6 years of advanced HIV infection, we can speculate this patient might have developed a disseminated cryptococcosis by primary infection.

In disseminated cryptococcosis, the recommended treatment consists of an induction phase with an amphotericin $\mathrm{B}$ formulation given intravenously combined with oral flucytosine for, at least, two weeks. This combination is associated with more rapid sterilization of CSF and better survival [33]. Unfortunately, we do not have flucytosine in our service. Thus, amphotericin B formulation combined with fluconazole at $800 \mathrm{mg}$ daily is a viable option in this circumstance.

Liposomal amphotericin B is preferable to conventional formulation, since it shows similar efficacy, but less toxicity [34]. Our patient developed acute renal failure after a week of treatment with amphotericin B deoxycholate. At discretion of assistant doctor, treatment was switched for fluconazole at $1200 \mathrm{mg}$ daily, according to guidelines recommendations [33]. The patient had a good response to the treatment. CSF cultures for fungi at one and two-weeks were negative. The symptoms disappeared completely with recovery of leucocytes and platelets counts. In the maintenance therapy of $\mathrm{CM}$, fluconazole is used to prevent relapses until an adequate immunological recovery. Our patient had an advanced HIV disease, as evidenced by his extremely low CD4 count, and several predictors of poor outcome of cryptococcal infection: a low baseline body weight, a poor baseline CSF inflammatory response $(<20$ cells $/ \mu \mathrm{L}$ of CSF), a low Karnofsky performance status at presentation and a disseminated disease with positive extraneural culture [35]. Taking into account these prognostic factors, at the decision of assistant doctor, the patient used a higher than usual dose of fluconazole (200 mg daily) in the maintenance phase, based on the Brazilian guidelines for management of cryptococcosis [33, 36].

In conclusion, bone marrow infection caused by Cryptococcus neoformans is uncommon. This etiology should be included for differential diagnosis in HIV-infected patients with fever and cytopenias, especially when CD4 T lymphocytes count is below 100 cells $/ \mu \mathrm{L}$. This case illustrates an atypical presentation of disseminated cryptococcosis with bone marrow involvement and asymptomatic meningitis, highlighting the role of bone marrow aspirate and biopsy study in HIV-infected patients with fever and pancytopenia for early diagnosis and adequate treatment of opportunistic infections.

\section{Abbreviations \\ AIDS: Acquired Immunodeficiency Syndrome; CM: Cryptococcal Meningitis; CNS: Central Nervous System; CrAg: Cryptococcal Antigen; CSF: Cerebrospinal Fluid; CT: Computed Tomography; DNA: Deoxyribonucleic Acid; HIV: Human Immunodeficiency Virus; ICP: Intracranial Pressure; MRI: Magnetic Resonance Imaging; PCR: Polimerase Chain Reaction; RFLP: Restriction Fragment Length Polymorphism; RI: Reference Interval; VDRL: Venereal Disease Research Laboratory; VNI: Cryptococcus neoformans genotype I}

\section{Acknowledgments}

We would like to thank the Hospital Giselda Trigueiro for technical assistance.

Funding

This case report received no specific grant from any funding agency in the public, commercial, or not-for-profit sectors.

\section{Availability of data and materials}

All data generated or analyzed during this study is included in this published article. This is a case report based on a patient taken care of Hospital Giselda Trigueiro. Data was obtained from the patient's chart. Signed consent was obtained for this case report. Evidence supporting the case report were obtained via PubMed.

Author's contributions

HTV was one of the patient's physician assistant and the major contributor in writing this manuscript. RCT, ALO and RMOSG performed the species and genotype identification of Cryptococcus isolate. RCT also contributed writing the manuscript. RDAS performed the bone marrow aspirate and biopsy and 
also did the hematological study. MGF performed the anatomopathological study of bone marrow biopsy. MBB was one of the patient's physician assistant and contributed writing the manuscript. All authors read and approved the final manuscript.

\section{Ethics approval and consent to participate} Not applicable.

\section{Consent for publication}

A written informed consent was obtained from the patient for publication of this case report and any accompanying images. Available on request.

\section{Competing interests}

The authors declare that they have no competing interests.

\section{Publisher's Note}

Springer Nature remains neutral with regard to jurisdictional claims in published maps and institutional affiliations.

\section{Author details}

${ }^{1}$ Department of Infectious Diseases, Hospital Giselda Trigueiro, Universidade Federal do Rio Grande do Norte, 110 Cônego Monte Street, Natal, Rio Grande do Norte RN 59037-170, Brazil. '2Department of Celular Biology and Genetics/Institute of Tropical Medicine, Universidade Federal do Rio Grande do Norte, Natal, Rio Grande do Norte RN 59078-970, Brazil. ²Department of Hematology, Universidade Federal do Rio Grande do Norte, 619a Nilo Peçanha Avenue, Natal, Rio Grande do Norte RN 59012-300, Brazil. ${ }^{4}$ Department of Pathology, Hospital Universitário Onofre Lopes, 600 Nilo Peçanha Avenue, Natal, Rio Grande do Norte RN 59012-300, Brazil.

Received: 20 July 2018 Accepted: 19 February 2019 Published online: 04 March 2019

\section{References}

1. Rajasingham, R., Smith, R. M., Park, B. J., et al. Global burden of disease of HIV associated cryptococcal meningitis: an updated analysis. Lancet Infect Dis 2017; 17(8), 873-881. Doi:https://doi.org/10.1016/S1473-3099(17)30243-8.

2. El Fane M, Badaoui L, Ouladlahsen A, et al. La cryptococcose au cours de I'infection à VIH. Journal de Mycologie Medicale. 2015;25(4):257-62. https:// doi.org/10.1016/j.mycmed.2015.09.008.

3. Crowe SM, Carlin JB, Stewart KI, et al. Predictive Value of CD4 Lymphocyte Numbers for the Development of Opportunistic Infections and Malignancies in HIV-Infected Persons. J Acquir Immune Defic Syndr. 1991;4(8):770-6.

4. Mirza, S. A., Phelan, M., Rimland, D., et al. The changing epidemiology of cryptococcosis: an update from population-based active surveillance in 2 large metropolitan areas, 1992-2000. Clin Infect Dis 2003; 36, 789-794. Doi: https://doi.org/10.1086/368091.

5. Tanaka PY, Hadad DJ, Barletti SC, et al. Bone marrow biopsy in the diagnoses of infectious and non-infectious causes in patients with advanced HIV infection. J Infect. 2007:54(4):362-6. https://doi.org/10.1016/j. jinf.2006.06.007.

6. Mccullough MJ, Disalvo AF, Clemons KV, Park P, Stevens DA. Molecular epidemioloy of Blastomyces dermatitidis. Clin Infect Dis. 2000;30:328-35. https://doi.org/10.1086/313649.

7. Meyer W, Castañeda A, Jackson S, Huynh M, Castañeda E, Arechavala A, et al. Molecular typing of IberoAmerican Cryptococcus neoformans isolates. Emerg Infect Dis. 2003;9:189-95. https://doi.org/10.3201/eid0902.020246.

8. Kidney Disease. Improving global outcomes (KDIGO). Acute kidney injury work group. KDIGO clinical practice guidelines for acute kidney injury. Kidney International Supplements. 2012;2:1.

9. Saag MS, Graybill RJ, Larsen RA, et al. Practice Guidelines for the Management ofCryptococcal Disease. Clin Infect Dis. 2000;30(4):710-8. https://doi.org/10.1086/313757.

10. Liss HP, Rimland D. Asymptomatic Cryptococcal Menigitis. Am. Rev. Respir. Dis. 1981;124:88-9.

11. Butler WT, Alling DW, Spickard A, Utz JP. Diagnostic and prognostic value of clinical and laboratory findings in cryptococcal meningitis. A follow-up study of forty patients. N. Engl. J. Med. 1964;270:59-67. https://doi.org/10. 1056/NEJM196401092700201.

12. Smilack JD, Bellet RE, Talman WT. Cryptococcal pleural effusion. JAMA. 1975; 232(6):639-41. https://doi.org/10.1001/jama.1975.03250060035020.
13. Temfack E, Bigna JJ, Luma HN, et al. Impact of Routine Cryptococcal Antigen Screening and Targeted Preemptive Fluconazole Therapy in Antiretroviral-naive Human Immunodeficiency Virus-infected Adults With CD4 Cell Counts <100/ $\mu \mathrm{L}$ : A Systematic Review and Meta-analysis. Clin. Infect. Dis ,ciy567.Doi:https://doi.org/10.1093/cid/ciy567.

14. French N, Gray K, Watera C, et al. Cryptococcal infection in a cohort of HIV1-infected Ugandan adults. AIDS. 2002;16(7):1031-8. https://doi.org/10.1097/ 00002030-200205030-00009.

15. WHO Rapid Advice. Diagnosis, prevention, and management of cryptococcal disease in HIV- infected adults, adolescents, And children. 2011. Available at: http://whqlibdoc.who.int/publications/2011/9789241502979_eng.pdf. Accessed 27 Nov 2018

16. Temfack E, Kouanfack C, Mossiang L, et al. Cryptococcal antigen screening in asymptomatic HIV-infected antiretroviral Naïve patients in Cameroon and evaluation of the new semi-quantitative Biosynex CryptoPS test. Front Microbiol. 2018;9:409. https://doi.org/10.3389/fmicb.2018.00409.

17. Chammard TB, Temfack E, Lortholary O, et al. Diagnostic and therapeutic strategies in cryptococcosis : impact on outcome. Mem Inst Oswaldo Cruz. 2018;113(7):e180050. https://doi.org/10.1590/0074-02760180050.

18. Graybill JR, Sobel J, Saag M, et al. Diagnosis and Management of Increased Intracranial Pressure in patients with AIDS and Cryptococcal meningitis. Clin Infect Dis. 2000;30(1):47-54. https://doi.org/10.1086/313603.

19. Johnston SRD, Corbett EL, Foster O, et al. Raised intracranial pressure and visual complications in AIDS patients with cryptococcal meningitis. J Infect. 1992;24:185-9. https://doi.org/10.1016/0163-4453(92)92954-H.

20. Shankar SK, Mahadevan A, Satishchandra P, et al. Neuropathology of HIV / AIDS with an overview of the Indian scene. Indian J Med Res. 2005;121(4): 468-88.

21. Kovacs, J. A., Kovacs, A. A., Polis, M., et al. Cryptococcosis in the acquired immunodeficiency syndrome. Ann Intern Med 1985; 103(4), 533-538. Doi: https://doi.org/10.7326/0003-4819-103-4- 533.

22. Quesada AE, Tholpady A, Wanger A, et al. Utility of bone marrow examination for workup of fever of unknown origin in patients with HIV/AIDS. J Clin Pathol. 2015;68(3):241-5. https://doi.org/10.1136/jclinpath-2014-202715.

23. Suner $L$, Mathis $S$. Disseminated cryptococcosis in bone marrow. Blood. 2014;123(20):3070

24. Nayal B, Veena, Niveditha S, et al. Detection of cryptococcosis in peripheral blood smear: A case report. Int J Appl Basic Med Res. 2011;1(2):116-7. https://doi.org/10.4103/2229-516X.91158.

25. Basu S, Marwaha N, Aggarwal V. Bone marrow cryptococcosis in a humanimmunodeficiency virus-negative patient. Br J Haematol. 2003;120(1): 2. https://doi.org/10.1046/j.1365-2141.2003.03890.x.

26. Radhakrishnan N. Bone Marrow Aspiration and Biopsy. Medscape. 2017. Available from: https://emedicine.medscape.com/article/207575-overview . Accessed 27 Nov 2018.

27. Garcia-Hermoso D, Janbon G, Dromer F. Epidemiological evidence for dormant Cryptococcus neoformans infection. J Clin Microbiol. 1999;37(10):3204-9.

28. Alanio A, Vernel-pauillac F, Sturny-leclère A, Dromer F. Cryptococcus neoformans host Adaptation : toward biological evidence of dormancy. MBio. 2015;6(2):e02580-14. https://doi.org/10.1128/mBio.02580-14.

29. Saha DC, Goldman DL, Shao X, et al. Serologic evidence for reactivation of cryptococcosis in solid-organ transplant recipients. Clin Vaccine Immunol. 2007;14(12):1550-4. https://doi.org/10.1128/CVI.00242-07.

30. Levitz SM. The ecology of Cryptococcus neoformans and the epidemiology of Cryptococcosis. Rev Infect Dis. 1991;13(6):1163-9. https://doi.org/10.2307/ 4456203.

31. Fessel WJ. Cryptococcal meningitis after unusual exposures to birds. N Engl J Med. 1993;328(18):1354-5. https://doi.org/10.1056/NEJM199305063281816.

32. Nosanchuk JD, Shoham S, Fries BC, et al. Evidence of zoonotic transmission of cryptococcus neoformans from a pet cockatoo to an immunocompromised patient. Ann Intern Med. 2000;132(3):205-8. https://doi.org/10.7326/0003-4819132-3-200002010-00006.

33. Panel on Opportunistic Infections in HIV-Infected Adults and Adolescents. Guidelines for the prevention and treatment of opportunistic infections in HIV-infected adults and adolescents: recommendations from the Centers for Disease Control and Prevention, the National Institutes of Health, and the HIV Medicine Association of the Infectious Diseases Society of America. Available at http://aidsinfo.nih.gov/contentfiles/lvguidelines/adult_oi.pdf . Accessed 6 June 2018.

34. Hamill RJ, Sobel JD, El-Sadr W, et al. Comparison of 2 doses of liposomal amphotericin B andconventional amphotericin B deoxycholate for 
treatment of AIDS-associated acute cryptococcal meningitis: a randomized, double blind clinical trial of efficacy and safety. Clin Infect Dis. 2010;51(2): 225-32. https://doi.org/10.1086/653606.

35. Anekthananon T, Manosuthi W, Chetchotisakd P, et al. Predictors of poor clinical outcome of cryptococcal meningitis in HIV-infected patients. Int J STD AIDS. 2011;22(11):665-70. https://doi.org/10.1258/ijsa.2011.010538.

36. Grupo do Consenso de Criptococose. Consenso em criptococose - 2008. Rev Soc Bras Med Trop. 2008;41(5):524-44. https://doi.org/10.1590/S003786822008000500022

Ready to submit your research? Choose BMC and benefit from:

- fast, convenient online submission

- thorough peer review by experienced researchers in your field

- rapid publication on acceptance

- support for research data, including large and complex data types

- gold Open Access which fosters wider collaboration and increased citations

- maximum visibility for your research: over $100 \mathrm{M}$ website views per year

At BMC, research is always in progress.

Learn more biomedcentral.com/submissions 